\title{
Self-Powered Neutron Detector Calibration Using a Large Vertical Irradiation Hole of HANARO
}

\author{
Myong-Seop Kim, Byung-Gun Park and Gi-Doo Kang
}

\begin{abstract}
A calibration technology of the self-powered neutron detectors (SPNDs) using a large vertical irradiation hole of HANARO is developed. The $40 \mathrm{Rh}-\mathrm{SPNDs}$ are installed on the polycarbonate plastic support, and the gold wires with the same length as the effective length of the rhodium emitter of the SPND are also installed to measure the neutron flux on the SPND. They are irradiated at a low reactor power, and the SPND current is measured using the pico-ammeter. The external gamma-rays which affect the SPND current response are analyzed using the Monte Carlo simulation for various irradiation conditions in HANARO. It is confirmed that the effect of the external gamma-rays to the SPND current is dependent on the reactor characteristics, and that it is affected by materials around the detector. The current signals due to the external gamma-rays can be either positive or negative, in that the net flow of the current may be either in the same or the opposite direction as the neutron-induced current by the rhodium emitter. From the above procedure, the effective calibration methodology of multiple SPNDs using the large hole of HANARO is developed. It could be useful for the calibration experiment of the neutron detectors in the research reactors.
\end{abstract}

Index Terms-HANARO, self-powered neutron detector (SPND), neutron irradiation, research reactor, Monte-Carlo simulation, calibration method

\section{INTRODUCTION}

$\mathrm{S}^{\mathrm{E}}$ ELF-Powered Neutron Detectors (SPNDs) have been widely used for monitoring the neutron flux in reactors as well as in irradiation facilities. In its simplest form, the detector operates on the basis of directly measuring the beta decay current following neutron capture [1]. Because the SPND doesn't need to use the external bias supply applied to the detector, it is used not only for a typical neutron detector in the nuclear power plants but also for real-time neuron flux monitoring in the research reactors [2].

For the neutron flux monitoring using the SPND, sensitivity that is an intrinsic characteristic of the detector is required. In general, the sensitivity which is provided by the manufacturer is used. However, when developing the SPND or using the SPND for research purposes, it is necessary to calibrate the

The authors are with the Neutron Utilization Research Division, Korea Atomic Energy Research Institute, Daejeon 34057, Korea (email: mskim@kaeri.re.kr; bgpark@kaeri.re.kr; dooki@kaeri.re.kr) sensitivity accurately. The sensitivity of the SPND is calibrated by irradiating the detector and measuring the current signals and the neutron flux in the reactors. A conventional approach for the SPND calibration is the irradiation one or several SPNDs in the reactor core and measurement the sensitivity [3], [4], [5], [6], [7]. In order to calibrate multiple SPNDs simultaneously, a large irradiation hole and precise calibration method for multiple SPNDs are required.

HANARO, a $30 \mathrm{MW}$ research reactor in KAERI, is a good tool for a determination of the sensitivity of the SPND. In order to estimate the sensitivity of the SPND precisely, the reactor should be operated at low-power, and in this situation, influence of the external $\gamma$-rays is not insignificant. In this paper, contribution of the external $\gamma$-rays was analyzed using the Monte Carlo simulation for various irradiation conditions in HANARO of the rhodium-based SPND.

\section{SENSITIVITY OF SPND}

General SPND consists of three parts of emitter, insulator, and collector. The emitter captures neutrons, and emits electrons that reach the external sheath after going through the insulator polarizing the device. The electrons can be collected using a current amplifier connecting the emitter to the sheath. The electric current of the SPND depends on the neutron fluxes at the detector location, and characteristics of the detector, which is called detector sensitivity. The sensitivity of SPND is generally defined as

$$
\mathrm{S}=\frac{I}{\phi}=\frac{I_{\beta}+I_{\gamma}+I_{\text {cable }}}{\phi}
$$

where $\phi$ is the neutron flux in the vicinity of the SPND location, $I$ is the current signal of the SPND, $I_{\beta}$ is the current signal by beta-decay after the $(n, \gamma)$ reaction, $I_{\gamma}$ is the current signal by $\gamma$-ray interaction, and $I_{\text {calbe }}$ is the current signal caused from the connecting cable, and can be considered negligible for standard SPND by compensated lead wire. $I_{\beta}$ is proportional to the neutron flux, whereas $I_{\gamma}$ is dependent on the reactor characteristics and affected by materials around the detector. The gamma response of the SPND owing to photoelectric or Compton effects produce electrons with enough energy to pass from the collector to the emitter or vice versa. Probability of both effects increases with atomic number and mass of electrodes materials [1]. Consequently, the current signals can 
be either positive or negative, in that the net flow of the current may be either in the same or the opposite direction as the neutron-induced current.

\section{REFERENCE MEASUREMENT}

\section{A. Preparation of Experiment}

For the calibration of SPND sensitivity using a large vertical irradiation hole of HANARO, an irradiation rig and an irradiation basket were designed and manufactured. The irradiation rig is composed of a body made of Aluminum (Al) -6061 , and a flexible extension hose to guide the signal cables from the irradiation hole to the electronics on the reactor pool. The irradiation basket is inserted into the irradiation rig with multiple SPNDs. Polycarbonate was used for the irradiation basket to minimize the delayed $\gamma$-rays from neutron activation. On the outer side of the cylindrical shape irradiation basket, there are $40 \mathrm{U}$-grooves to mount the multiple SPNDs. In addition, grooves of $0.1 \mathrm{~mm}$ are provided between the grooves on which the SPNDs are mounted too install neutron monitors.

Sensitivity calibration is performed for the SPNDs with rhodium (Rh) emitter. The specifications of the SPND used at the sensitivity calibration are summarized in Table 1.

\section{B. Measurement of SPND Sensitivity at Various Positions in the Large Vertical Hole}

SPND sensitivities at various positions in the large vertical hole were measured and calibrated. The $40 \mathrm{Rh}$-SPNDs were installed on the irradiation basket and irradiated at a low reactor power about $1 \mathrm{~kW}$. Fig. 1 shows the schematic of the multiple SPND calibration configurations in the large vertical hole of HANARO. During the irradiation of the SPNDs, all of the SPND current signals were collected for $16670 \mathrm{~s}$ using the Keithley 6517A picoammeter. In the measurement, a ground connection box was used to reduce the charging effect of the SPNDs. In addition a shielding box of copper was used to remove the noise which can be easily captured by long metallic SPND sheath.

The neutron flux during the irradiation was determined by activation of gold $\mathrm{Au}$ ) wires with the same length as the effective length of the $\mathrm{Rh}$ emitter. The Au wire has decayed about 10 days after the end of irradiation, and the $\gamma$-ray

TABLE I

SPND SPECIFICATIONS

\begin{tabular}{|c|c|}
\hline Parameters & Figures \\
\hline \multicolumn{2}{|l|}{ Materials } \\
\hline Emitter & $\mathrm{Rh}$ \\
\hline Insulator & $\mathrm{Al}_{2} \mathrm{O}_{3}$ \\
\hline Collector & Inconel-600 \\
\hline Core wire & Inconel-600 \\
\hline \multicolumn{2}{|l|}{ Dimensions } \\
\hline Diameter of core wire & $0.25 \mathrm{~mm}$ \\
\hline Diameter of emitter & $0.46 \mathrm{~mm}$ \\
\hline Outer diameter of insulator & $1.02 \mathrm{~mm}$ \\
\hline Outer diameter of collector & $1.56 \mathrm{~mm}$ \\
\hline Effective length of emitter & $400 \mathrm{~mm}$ \\
\hline Cable length & $35.8 \mathrm{~m}$ \\
\hline
\end{tabular}

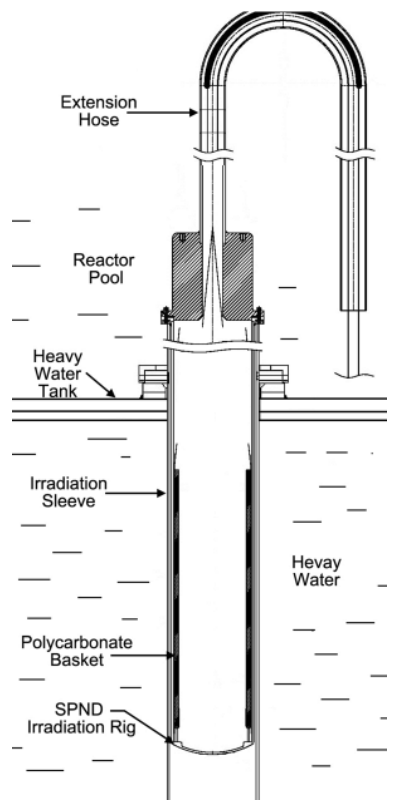

Fig. 1. Schematic of the multiple SPND calibration configuration in the large vertical hole of HANARO.

spectrum from the irradiated $\mathrm{Au}$ wire was measured for 1 hours of live time by using an HPGe detector. In the measured spectrum, peak area of $411.8 \mathrm{keV} \gamma$-ray from the Au-198 was analyzed and used to determine the saturation activity of the $\mathrm{Au}$ wire. The neutron flux at the position of the SPND was determined by averaging the neutron fluxes determined by the $\mathrm{Au}$ wires on both sides of the SPND.

Fig. 2 shows the measured neutron flux (Westcott) and determined sensitivity of SPND at each irradiation position. As shown in the Fig. 2, the maximum neutron flux was recorded at position 35, which was the nearest position to the reactor core. The measured sensitivities of SPNDs were $(3.8 \sim 5.4) \times 10^{-20}$ $\mathrm{A} / \mathrm{n} / \mathrm{cm}^{2}-\mathrm{s}$, and the standard deviation was 0.468 . Because all SPNDs have the same specification, theoretically they should have the same sensitivity regardless of the irradiation position. However, the measured sensitivity is apparently dependent on the irradiation position. The sensitivity is relatively high at position where the neutron flux is low, and low at position where the neutron flux is high.

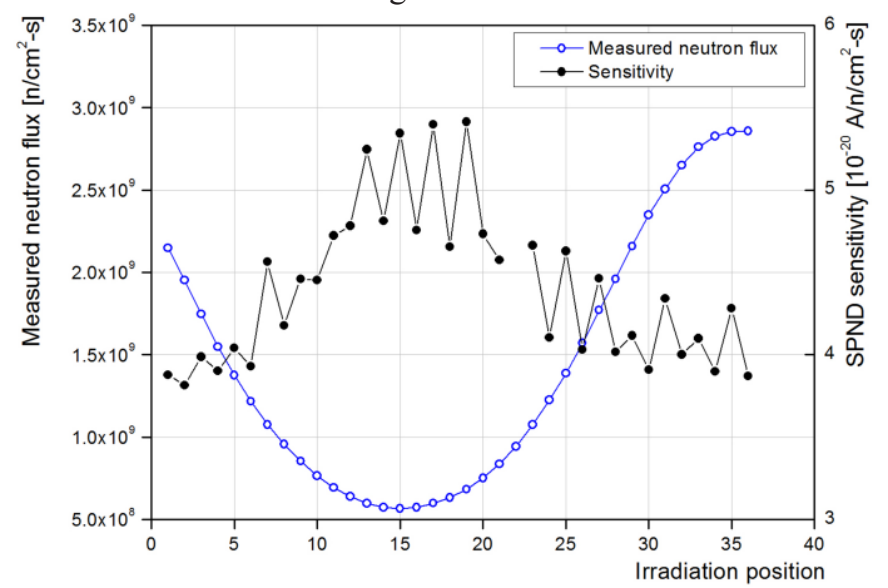

Fig. 2. Measured neutron flux and sensitivity of SPND, vs. the irradiation position. 


\section{EVALUATION OF SPND CURRENT RESPONSE USING MONTE CARLO SIMULATION}

In order to analyze the factors which can affect the SPND current response on the irradiation position, the Monte Carlo simulation for various irradiation conditions in HANARO was performed.

\section{A. Modeling of the Measurement}

The MCNP equilibrium core model was employed for a detailed whole core representation of the HANARO. In the core model, the isotopic density distributions of 13,104 fuel segments of HANARO core were investigated by the HANARO fuel management system, whose major components are WIMS and VENTURE codes. Based on the burnup dependent nuclide number density, power distribution and burnup distribution data from the WIMS and VENTURE codes, the MCNP model for HANARO burned-core in the middle of the 59th operation cycle was generated. The control rod position of the core model is $350 \mathrm{~mm}$ which is the distance from the bottom of its fully-inserted position. In the calculation, the reactor power was assumed to be $1 \mathrm{~kW}$ as in the measurement.

Fig. 3 shows the MCNP model for the SPND. The main components of the SPND are Rh emitter, an Inconel sheath collector, an aluminum oxide $\left(\mathrm{Al}_{2} \mathrm{O}_{3}\right)$ insulator and an Inconel wire. In the SPND modeling, geometry and material composition of each component were based on the SPND that was used for the reference measurement. In the Fig. $3, R_{e}, R_{i}$ and $\mathrm{R}_{\mathrm{c}}$ represent the radius of emitter, insulator and collector, respectively. $\mathrm{Rh}$ emitter of $40 \mathrm{~cm}$ length and the insulator and collector of $50 \mathrm{~cm}$ length were modeled for MCNP calculation.

An irradiation rig and basket for the SPND irradiation were assumed in a cylindrical shape. Top views of the models of the irradiation rig and basket are shown in Fig. 4. Outside of the irradiation rig, there is an $\mathrm{Al}$ sleeve that protects the surface of the heavy water reflector tank from the rig. And there is light water between the $\mathrm{Al}$ sleeve and the irradiation rig and between the irradiation rig and the irradiation basket. In addition, light water is filled inside the irradiation basket. In the calculation, 40 irradiation positions were located in a circle along the irradiation basket. The SPNDs are located at the center of each U-groove of the irradiation basket. The axial position of the center of the $\mathrm{Rh}$ emitter was assumed to be $12.5 \mathrm{~cm}$ from the longitudinal center of the reactor core.

\section{B. Calculation of the Transport of Neutrons and Photons in the Measurement}

In order to analyze the factors which can affect the SPND current response, the spatial distributions of the neutron flux, photon flux, and neutron capture reaction and $\gamma$-ray interaction rates in each component of the SPND were calculated using the MCNP6 code. The transport calculation was performed in criticality mode. F4 tallies and F4 tallies with multipliers for tallying the reaction rate of the MCNP code were used to calculate the flux and reaction rate, respectively.

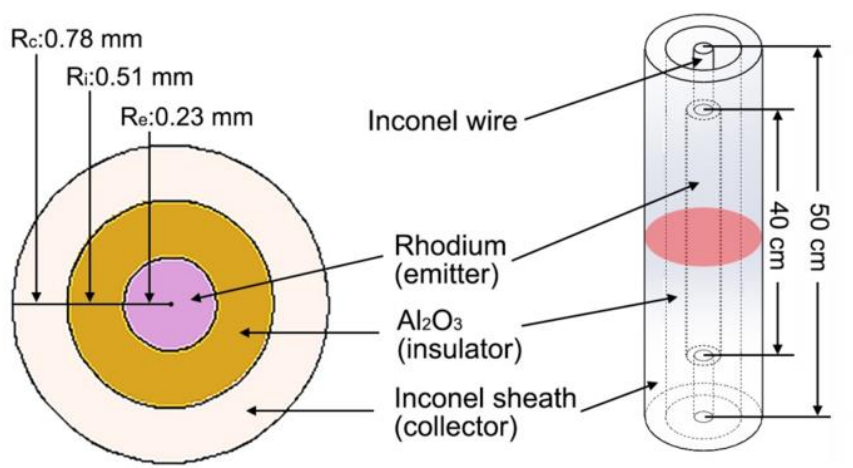

Fig. 3. Configuration of SPND calculation model (not to scale).

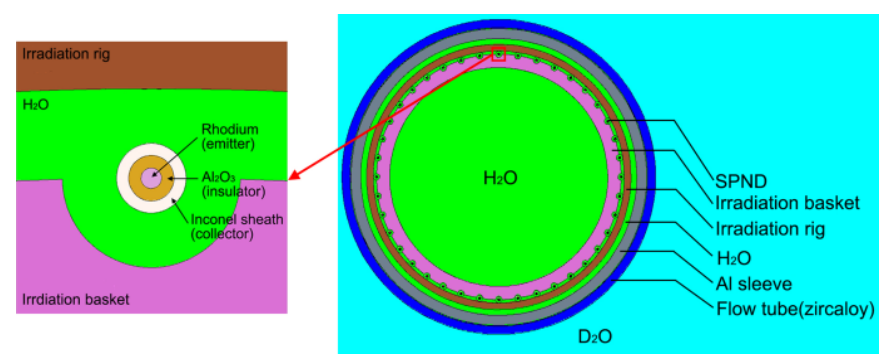

Fig. 4. Top view sketches of the irradiation rig, irradiation basket and SPND of the calculation model.

Fig. 5 shows the calculation result of the normalized neutron flux at $\mathrm{Rh}$ emitter of the SPNDs, which were installed at different positions $(1 \sim 40)$ of the irradiation basket. As shown in the figure, the maximum neutron flux was recorded at position 11, which was the nearest position to the reactor core. Measured neutron flux at each position is described with the calculated one in Fig. 5. In order to compare with the calculation results, the irradiation positions of the measurement are displayed in accordance with the calculation results. The calculated spatial distribution of the neutron flux is similar to the measured one. Maximum difference of the neutron flux between the calculation and measurement is $11 \%$. The inconsistency is caused by the neutron self-shielding effect. In the calculation, diameter of the $\mathrm{Rh}$ emitter was $0.46 \mathrm{~mm}$ which can make the self-shielding correspondingly higher than the $\mathrm{Au}$ wire of $0.01 \mathrm{~mm}$ diameter in the measurement. Moreover, the $\mathrm{Rh}$ emitter is surrounded by the insulator and the collector materials, and thus some of neutrons are shielded by the surrounding materials in the calculation.

Fig. 6 shows the calculated neutron and photon flux distributions at each component of the SPNDs at 40 irradiation positions. As shown in Fig. 6, the maximum neutron flux and photon flux were recorded at position 11 whereas the minimum fluxes were recorded at position 31 or 32 , which was the opposite the direction to position 11. Among the four components of the SPND, neutron flux is the highest at the Inconel sheath, followed by the insulator, the emitter and the Inconel wire, regardless of the irradiation position. In contrast, the photon fluxes of the collector, the insulator and the emitter did no show a significant difference for the same irradiation position except for the Inconel wire. This is because the $\gamma$-rays from the fuels and the prompt $\gamma$-rays from neutron capture in the materials near SPND are not attenuated significantly when they incident to the Rh emitter. In consideration of the neutron 


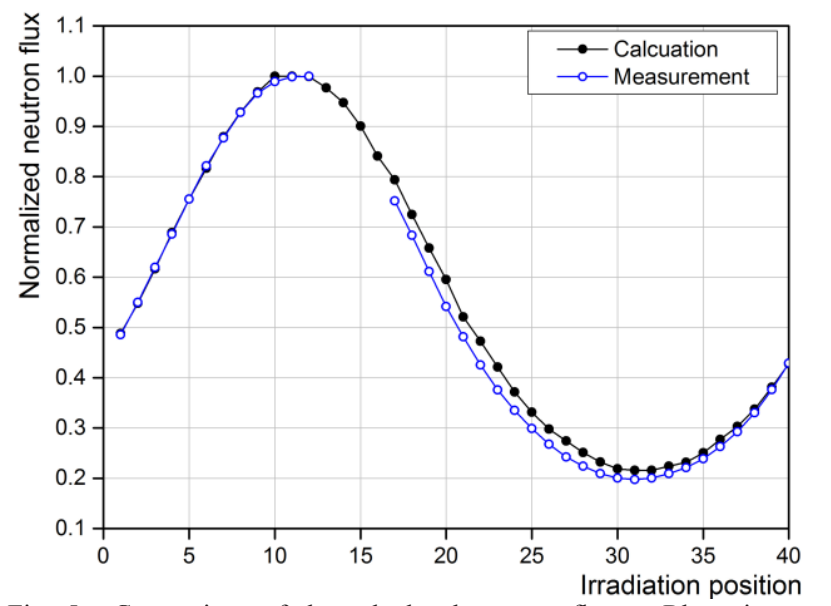

Fig. 5. Comparison of the calculated neutron flux at $\mathrm{Rh}$ emitter and measured one.

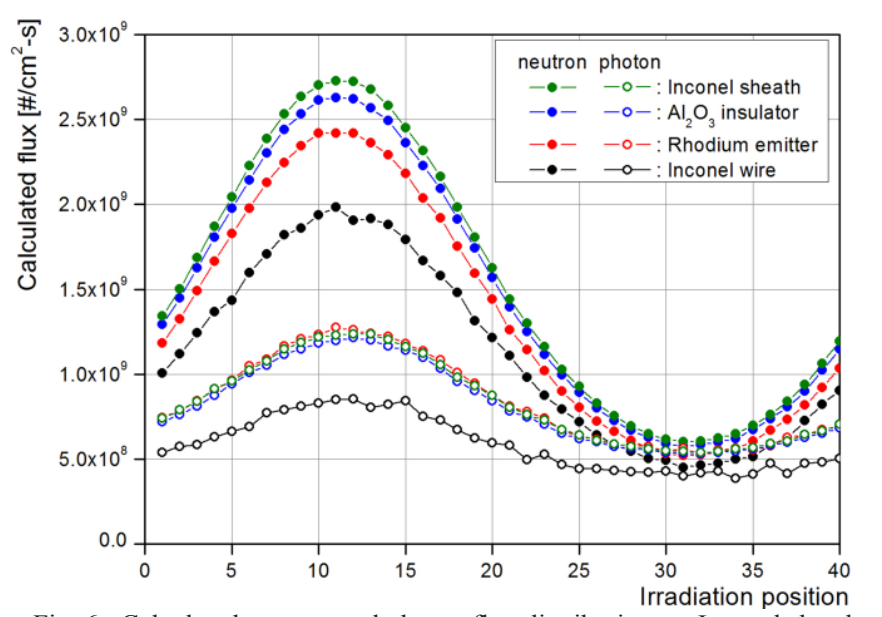

Fig. 6. Calculated neutron and photon flux distributions at Inconel sheath, $\mathrm{Al}_{2} \mathrm{O}_{3}$ insulator, Rhodium emitter and Inconel wire for 40 SPNDs

and photon fluxes as a function of the irradiation position, the ratio of the neutron flux at position 31 to position 11 for the $\mathrm{Rh}$ emitter $\left(\phi_{n, \text { emitter31 }} / \phi_{n, \text { emitter11 }}\right)$ is 0.22 , whereas the ratio of the neutron flux at position 31 to position 11 for the $\mathrm{Rh}$ emitter $\left(\phi_{\gamma, \text { emitter31 }} / \phi_{\gamma, \text { emitter11 }}\right)$ is 0.44 . This means that there is flux gradient in the large vertical hole in radial direction, and the neutron flux is decreased significantly by water in the irradiation basket from position 11 to position 31 . However, the $\gamma$-rays are correspondingly less affected by water in the irradiation basket than neutrons.

Neutron capture $(\mathrm{n}, \gamma)$ reaction rate and total $\gamma$-ray $(\gamma$, tot $)$ interaction rate distributions for 40 SPNDs are shown in Fig. 7. The ratio of the minimum position to maximum position can be estimated in the same manner as for the ratio of neutron and photon fluxes. For the $\mathrm{Rh}$ emitter, $\mathrm{RR}_{\mathrm{n}, \mathrm{emitter31}} / \mathrm{RR}_{\mathrm{n}, \mathrm{emitter11}}$ is 0.23 , which is similar to the $\phi_{\mathrm{n}, \mathrm{emitter31}} / \phi_{\mathrm{n}, \mathrm{emitter11}}$. On the other hand, $\mathrm{RR}_{\gamma, \text { emitter31 }} / \mathrm{RR}_{\gamma, \text { emitter11 }}$ is 0.51 , which is slightly higher than $\phi_{\gamma, \text { emitter31 }} / \phi_{\gamma, \text { emitter11 }}$.

\section{Analysis of SPND Current Response from the $(n, \gamma)$ and $(\gamma$, tot $)$ Reaction Rates}

Among the components of the SPND, the $(n, \gamma)$ reaction at the $\mathrm{Rh}$ emitter is dominant, and insulator and Inconel wire can be

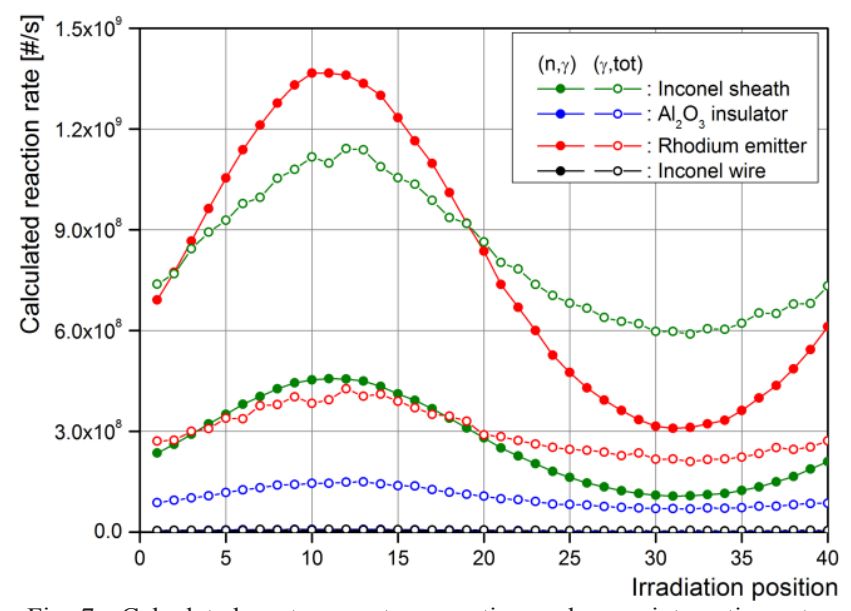

Fig. 7. Calculated neutron capture reaction and $\gamma$-ray interaction rates at Inconel sheath, $\mathrm{Al}_{2} \mathrm{O}_{3}$ insulator, Rhodium emitter and Inconel wire for 40 SPNDs

negligible. The spatial distribution of the $(n, \gamma)$ reaction rate at the $\mathrm{Rh}$ emitter is equivalent with that of the neutron flux. Therefore, it can be regarded that the $(n, \gamma)$ reaction at the $\mathrm{Rh}$ emitter is irrelevant to the difference of the SPND sensitivity according to the irradiation position.

The $(n, \gamma)$ reaction rate at the Inconel sheath are approximately $1 / 3$ of those at the $\mathrm{Rh}$ emitter regardless of the irradiation position. In order for the neutrons that are captured in the Inconel sheath to contribute to the SPND current, electrons after beta-decay should be reached the Rh emitter. In this case, negative current is produced and thereby a part of positive current by electrons from the $\mathrm{Rh}$ emitter is compensated. However, a diameter of the $\mathrm{Rh}$ emitter is less than Inconel sheath, therefore partial electrons from Inconel sheath can be reached the $\mathrm{Rh}$ emitter. Furthermore, current-contributing electron should have energy greater than EMIN which is the minimal energy to pass the insulator. From the Warren's model [8], the EMIN of the SPND in this study is $300 \mathrm{keV}$ which is calculated by considering the diameter and thickness of the $\mathrm{Rh}$ emitter and $\mathrm{Al}_{2} \mathrm{O}_{3}$ insulator. $\mathrm{Cr}-55, \mathrm{Fe}-59$ and Ni-65 are main radioisotopes which are produced after $(n, \gamma)$ reaction in the Inconel sheath, and energies of the released electrons are higher than $300 \mathrm{keV}$. However, abundance and (n, $\gamma)$ reaction cross-sections of the parent nuclides are negligibly small. As a consequence, it is not needed to consider the $(\mathrm{n}, \gamma)$ reaction in the Inconel sheath to the current sensitivity of the SPND.

As shown in Fig. 7, $(\gamma$, tot $)$ interaction rate is the highest at the Inconel sheath, followed by the Rh emitter, the insulator and the Inconel wire, regardless of the irradiation position. In order to contribute the SPND current, electrons from the Rh emitter and Inconel sheath should be reached the Inconel sheath and Rh emitter, respectively. The electrons from the insulator can be reached both $\mathrm{Rh}$ emitter and Inconel sheath. To estimate the SPND current response by the $(\gamma$, tot $)$ interaction, it is assumed that 1$)$ electrons produced by the $(\gamma$, tot $)$ interaction can escape from the initial material 2) direction of the released electrons is isotropic 3) released electrons can pass the insulator. Considering the geometry of the SPND, the most electrons from the $\mathrm{Rh}$ emitter can be reached the Inconel sheath, and 
contribute the positive SPND current. In contrast, partial electrons from the Inconel sheath can be reached the Rh emitter because the diameter of the emitter is quite small. In the case of the insulator, partial electrons reach the $\mathrm{Rh}$ emitter, and most electrons reach the Inconel sheath.

The probability of electrons from the Inconel sheath reaching the $\mathrm{Rh}$ emitter was estimated by using the Monte Carlo method. In the estimation the SPND model of the MCNP calculation was used. Electrons were emitted to isotropic direction from the Inconel sheath region, and the electrons reaching the $\mathrm{Rh}$ emitter were counted. The probability of electron reaching was estimated to be 0.0753 . This value is used as a correction factor to the $(\gamma$, tot $)$ interaction rate at the Inconel sheath. As a result, $(\gamma$, tot $)$ interaction rate at the Inconel sheath in Fig. 7 is decreased $7.53 \%$ of the initial value, and then the dominant contribution to the SPND current is $(\gamma$, tot $)$ interaction rate at the Rh emitter.

\section{Correction of External $\gamma$-rays to the SPND Current}

Unless the contribution of the external $\gamma$-rays to the SPND current is the same for all irradiation positions, it cannot be easy to correct the external $\gamma$-rays because different correction factors should be used for each irradiation position. The external $\gamma$-rays can be classified into $1^{\text {st }}$ and $2^{\text {nd }} \gamma$-rays. The $1^{\text {st }}$ $\gamma$-rays are emitted from the fission product and activated structural materials in the reactor, and they can be produced in zero power of the reactor. Therefore the contribution of the $1^{\text {st }}$ $\gamma$-rays can be corrected by subtracting the SPND current measured before operation of the reactor.

Whereas the $2^{\text {nd }} \gamma$-rays are depends on the reactor power. If the ratio of $I_{\gamma}$ to the $I_{\beta}$ in (1) is same at each position, the sensitivity of the SPND can be determined irrelevant to the irradiation position. However, as shown in Fig. 7, $\mathrm{RR}_{\gamma, \text { emitter11 }} / \mathrm{RR}_{\mathrm{n}, \mathrm{emitter11}}$ is 0.29 at position 11 , but $\mathrm{RR}_{\gamma, \mathrm{emitter31}} / \mathrm{RR}_{\mathrm{n}, \mathrm{emitter31}}$ is increases 0.70 at position 31 . In this case, therefore, contribution of $2^{\text {nd }} \gamma$-rays to the SPND positive current increases at position 31 , therefore the sensitivity of SPND at position 31 can be determined higher than that at position 11. In the reference experiment, the sensitivity of SPND installed at far from the reactor core was measured $40 \%$ higher than that at the nearest position to the reactor core. That is the $\gamma$-rays can be travel longer than neutrons in the irradiation basket. Contribution of the $2^{\text {nd }} \gamma$-rays can be reduced by removing water in the irradiation basket, and increasing the path length of the neutrons.

\section{E. Estimation of Corrected SPND Sensitivity}

The irradiation baskets not containing light water inside the basket were considered to investigate the sensitivities of the SPNDs at each irradiation position. Using the MCNP code, the $(n, \gamma)$ reaction rate and $(\gamma$, tot $)$ interaction rate distributions of the SPND components at each irradiation position were calculated. Calculation model is same with the previous one except the water in the irradiation basket was replaced to air.
Fig. 8 shows the spatial distribution of the $(n, \gamma)$ reaction rate and $(\gamma$, tot) interaction rate for 40 SPNDs installed at the irradiation basket without water. In the figure, $(\gamma$, tot $)$ interaction rate of the Inconel sheath was corrected distribution by using the correction factor of 0.0753 . In this case, neutron absorption and scattering by water disappear. The $(\mathrm{n}, \gamma)$ reaction rate at the $\mathrm{Rh}$ emitter at position 31 was $66.6 \%$ of that at position 11 . The ratios of $(\gamma$, tot $)$ to $(n, \gamma)$ rate at the $\mathrm{Rh}$ emitter are the same within $2 \%$ at all positions, for example $\mathrm{RR}_{\gamma, \text { emitter11 }} / \mathrm{RR}_{\mathrm{n}, \text { emitter11 }}$ and $\mathrm{RR}_{\gamma, \text { emitter31 }} / \mathrm{RR}_{\mathrm{n} \text {,emitter31 }}$ are 0.23 and 0.25 , respectively.

From the calculation results, sensitivity of the SPND was defined as

$$
\mathrm{S}=\frac{R R_{n, \text { emitter }}+R R_{\gamma, \text { emitter }}}{\phi_{n, \text { emitter }}}
$$

where, $\mathrm{S}$ is the sensitivity, $R R_{n}$ is the $(\mathrm{n}, \gamma)$ reaction rate, $R R_{\gamma}$ is the $(\gamma$, tot $)$ interaction rate, and $\phi$ is the neutron flux. The sensitivity was estimated for the SPNDs installed at the irradiation basket with water and without water conditions. Calculation results are shown in Fig. 9. As shown in Fig. 9, the spatial distribution of the sensitivity of the irradiation basket with water is more than $20 \%$ difference in the average. However the spatial distribution of the sensitivity of the irradiation basket without water is within $4 \%$ in the average for all positions.

\section{CALIBRATION OF SPND SENSITIVITY}

The sensitivities of multiple SPNDs were calibrated based on the calibration method determined from the MCNP calculation. In this measurement, the irradiation basket without water was used. Additionally, before raising the reactor power, the current of the SPNDs in zero reactor power was measured for $300 \mathrm{~s}$. After measurement of zero power current, reactor power was increased to $1.5 \mathrm{~kW}$ and the current of the SPNDs were measured for $10866 \mathrm{~s}$. In this experiment, the nearest irradiation position to the reactor core was 35 .

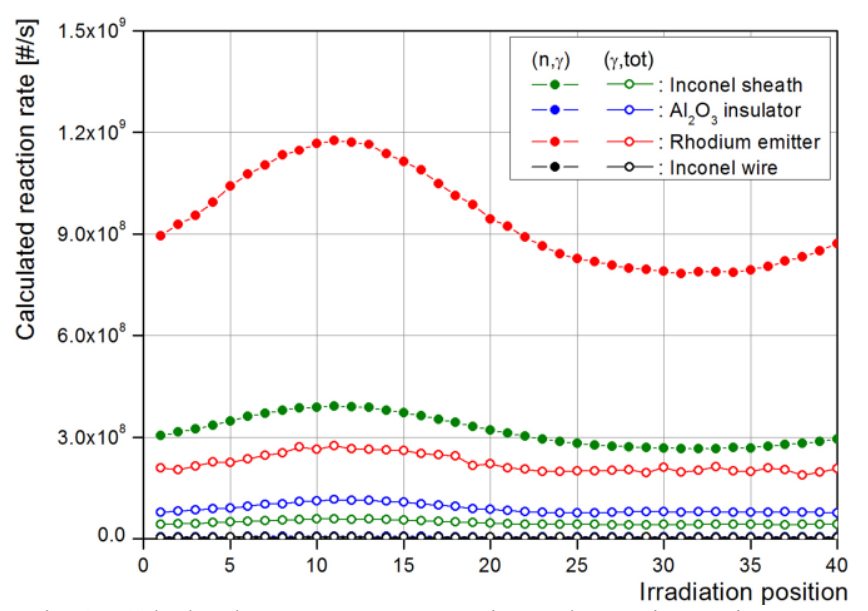

Fig. 8. Calculated neutron capture reaction and $\gamma$-ray interaction rates at each irradiation position of the irradiation basket without water. 


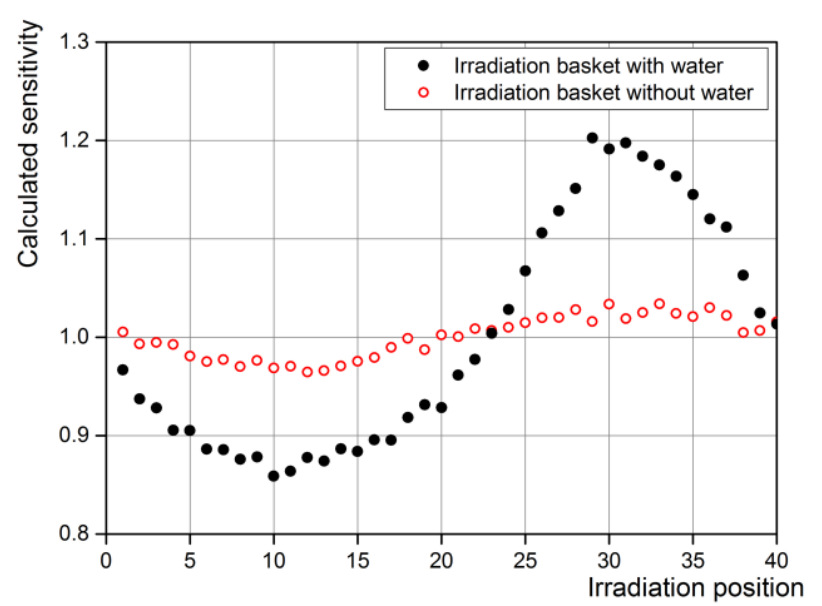

Fig. 9. Calculated sensitivities of 40 SPNDs installed at the irradiation baskets with water and without water.

Fig. 10 shows the spatial distributions of the SPND current in the zero power condition, $1.5 \mathrm{~kW}$ reactor power. The current in zero power subtracted data are also depicted in the figure. In the zero power measurement, only $1^{\text {st }} \gamma$-rays contribute to the SPND current. The measured current of the SPNDs were $9 \sim 25$ $\mathrm{pA}$, which depends on the irradiation position. In the $1.5 \mathrm{~kW}$ reactor power, neutrons, $1^{\text {st }} \gamma$-rays and $2^{\text {nd }} \gamma$-rays contribute to the SPND current together. In this condition, the current of the SPNDs were $70 \sim 130 \mathrm{pA}$. It is found that $10 \sim 20 \%$ of the SPND current is come from the $1^{\text {st }} \gamma$-rays. The subtracted current distribution shows more smooth shape than before subtraction.

The sensitivity of the SPND was determined by using the subtracted current and measured neutron flux. Spatial distributions of the measured sensitivity and calculated one which is shown in Fig. 9 are shown in Fig. 11. For comparison, number of irradiation position in the measurement is adjusted to the calculation. Distributions of the measured and calculated sensitivities are equivalent for irradiation positions. In the measured result, sensitivities of SPNDs installed odd number irradiation positions are larger than those installed even number irradiation positions. This is because the SPNDs at the odd position and the SPNDs at the even position were made of different manufacturers. When compared by odd positions and even positions separately, the deviation of the sensitivity to the average value is within 5\%. The standard deviation of the measured sensitivities was 0.072 , which is improved value than 0.468 for the reference measurement.

\section{CONCLUSION}

We described a method for calibrating sensitivity of multiple SPNDs installed at a large vertical hole of HANARO. Employing Monte Carlo simulation the contribution of the $\gamma$-rays to the current signal was estimated at various positions of the large vertical hole. The sensitivity variations of the multiple SPNDs were significantly improved by removing the contribution of $1^{\text {st }} \gamma$-rays emitted from the core, and by using the irradiation basket without water. The procedure can be useful for the calibration experiment of the neutron detectors in the research reactors.

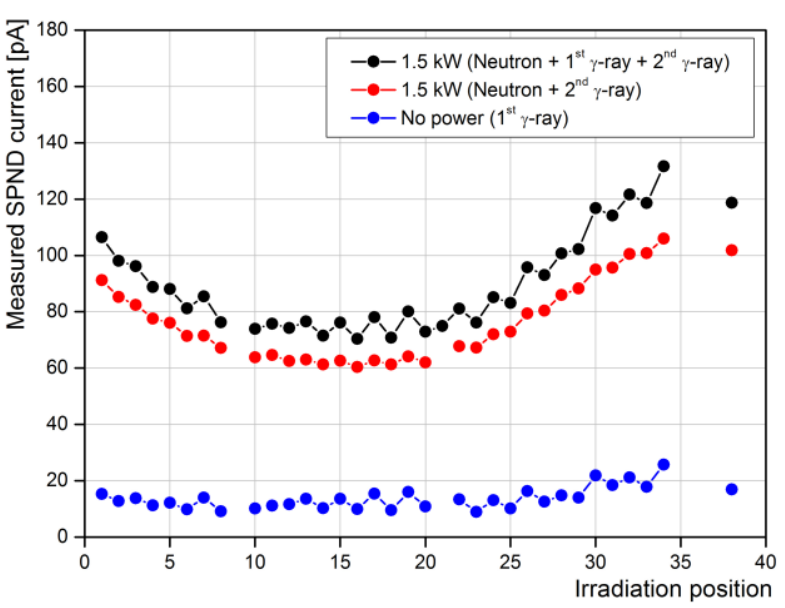

Fig. 10. Calculated neutron capture reaction and $\gamma$-ray interaction rates at each irradiation position of the irradiation basket without water.

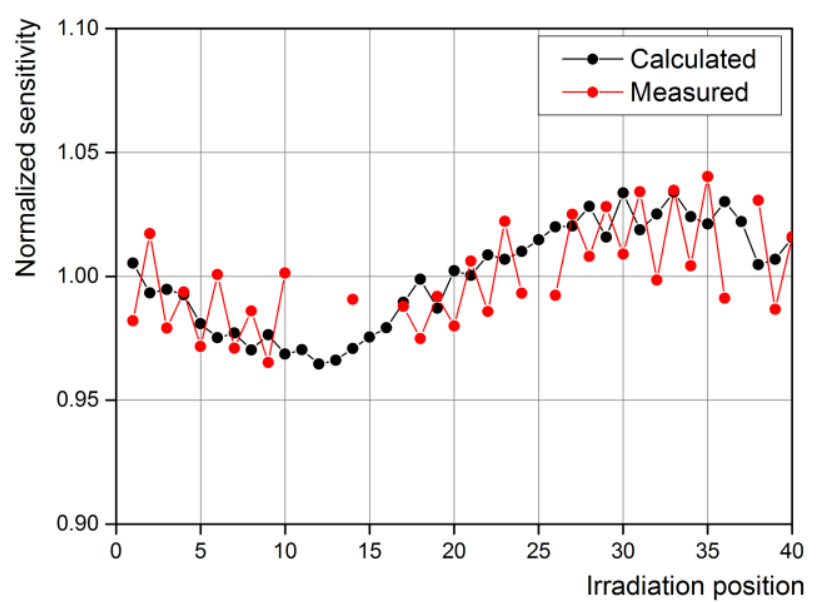

Fig. 11. Calculated neutron capture reaction and $\gamma$-ray interaction rates at each irradiation position of the irradiation basket without water.

\section{REFERENCES}

[1] G. F. Knoll, Radiation Detection and Measurement, New York: John Wiley \& Sons, 2000.

[2] M. S. Kim and G. D. Kang, "Precise Control of Neutron Irradiation Fluence in the Neutron Transmutation Doping Process in HANARO Using SPND and Zirconium Foils", IEEE Trans. Nuclear Science, vol. 63, no. 3, pp. 1625-1629, 2016

[3] M. N. Baldwin and J. E. Rogers, "Calibration of the Self-Powered Neutron Flux Monitor in a Simulated PWR Lattice", IEEE Trans. Nuclear Science, vol. 16, no. 1, pp. 171-176, 1969

[4] N. P. Goldstein, "A Monte-Carlo Calculation of the Neutron Sensitivity of Self-Powered Detectors”, IEEE Trans. Nuclear Science, vol. 20, no. 1, pp. 549-556, 1973

[5] L. A. Banda, "Operational Experience in Rhodium Self-Powered Detectors", IEEE Trans. Nuclear Science, vol. NS-26, no. 1, pp. 910-915, 1979

[6] P. S. Rao and S. C. Misra, "Neutron Sensitivity of Vanadium Self Powered Neutron Detectors" Nucl. Instr. and Meth. in Phys. Res. A 253, pp. 57-60, 1986

[7] M. Alex and M. D. Ghodgaonkar, "Development of an Inconel Self Powered Neutron Detector for In-Core Reactor Monitoring", Nucl. Instr. and Meth. in Phys. Res. A 574, pp. 127-132, 2007

[8] H. D. Warren, "Calculational model for self-powered neutron detector, Nucl. Sci. Eng., Vol. 48, pp. 331-342, 1972 